\title{
Investigation of the $\alpha$-Dicarbonyl Compounds in Some Snack Foods by HPLC Using Precolumn Derivatization with 4-Nitro-1,2-Phenylenediamine
}

\author{
Elif Ede Çintesun ${ }^{1,2} \mathbb{( D}$, Sena Nur Tanyıldız ${ }^{2}$, , Hatice Yıldırım ${ }^{2}(\mathbb{D})$, Ömer Faruk Mızrak ${ }^{2} \mathbb{D}$, Mustafa \\ Yaman $2, *$ (iD \\ 1 Istanbul Medipol University, Institue of Health Sciences, Department of Nutrition and Dietetics, Turkey; \\ elifedecintesun@gmail.com, elif.ede@izu.edu.tr (E.E.C.); \\ 2 Istanbul Sabahattin Zaim University, Faculty of Health Sciences, Department of Nutrition and Ditetetics; \\ senanurtan@hotmail.com (S.N.T.); haticeyildirim96@hotmail.com (H.Y.); omer.mizrak@izu.edu.tr (O.F.M.); \\ mustafa.yaman@izu.edu.tr (M.Y.); \\ * Correspondence: mustafa.yaman@izu.edu.tr (M.Y.);
}

Scopus Author ID 57213160335

Received: 22.03.2021; Revised: 10.05.2021; Accepted: 15.05.2021; Published: 18.06.2021

\begin{abstract}
Snack foods are widely consumed in today's modern diet. Food processing techniques and food composition may increase advanced glycation products (AGEs) in snack foods. The present study aimed to determine the most potent precursors of AGEs in snack foods. For this purpose, commonly consumed some snacks foods were obtained from markets in Istanbul, Turkey. The amount of $\alpha$ dicarbonyl compounds ( $\alpha$-DCs,) glyoxal (GO), and methylglyoxal (MGO) were determined by highperformance liquid chromatography. The measured amount of GO and MGO ranged between 4-684 $\mu \mathrm{g}$ / $100 \mathrm{~g}$ and 28-1573 $\mu \mathrm{g} / 100 \mathrm{~g}$ in snack foods, respectively. In our study, high levels of MGO were detected in wafer hazelnut chips with cheese and peanuts. Due to their high-fat content, the formation of GO and MGO may occur through lipid peroxidation. In addition, the fragmented state of hazelnuts and peanuts in samples may increase lipid peroxidation. Free sugar content in Turkish delight and cake with fruit might contribute to the $\alpha$-DCs formation by caramelization reaction due to high temperature. In conclusion, snack products that are frequently consumed have many unfavorable features for health. It is important to limit snack food consumption in terms of reducing AGEs exposure.
\end{abstract}

Keywords: advanced glycation end products; glyoxal; methylglyoxal; snack foods; HPLC.

(C) 2021 by the authors. This article is an open-access article distributed under the terms and conditions of the Creative Commons Attribution (CC BY) license (https://creativecommons.org/licenses/by/4.0/).

\section{Introduction}

Nowadays, with the changes in dietary habits, the consumption of processed foods has increased. Along with these changes, high-temperature cooking processes have led to increased exposure to advanced dietary glycation end products (AGEs). [1,2]. AGEs are heterogeneous groups of molecules formed as a result of a non-enzymatic reaction between reducing sugars and free amino groups of protein, lipid, or nucleic acids [3]. This process is also known as glycation or Maillard Reaction (MR) [4]. At the early stage of MR, the Schiff base is formed due to the condensation reaction between the carbonyl group of the reducing sugars and the free amino groups of the proteins. [5]. The Schiff base then converts to ketamine's known as Amadori products [6]. The degradation of Amadori products results in highly reactive $\alpha$ dicarbonyl compounds ( $\alpha$-DCs) formation such as 1-deoxyglucose, 3-deoxyglucose (3-DGO), glyoxal (GO), and methylglyoxal (MGO) 2 [7]. $\alpha$-DCs, which are AGE precursors, form AGEs 
in the 'advanced' processes of the reaction. [8]. AGEs can be formed by glucose oxidation lipid peroxidation and caramelization as well as Maillard reaction (Figure 1) [9]. Carboxymethyllizine (CML), carboxyethyllizine (CEL), methylglyoxal lysine dimer (MOLD), deoxyglucose lysine dimer (GOLD), pentosidine and pyrimidine are the known AGEs [10].

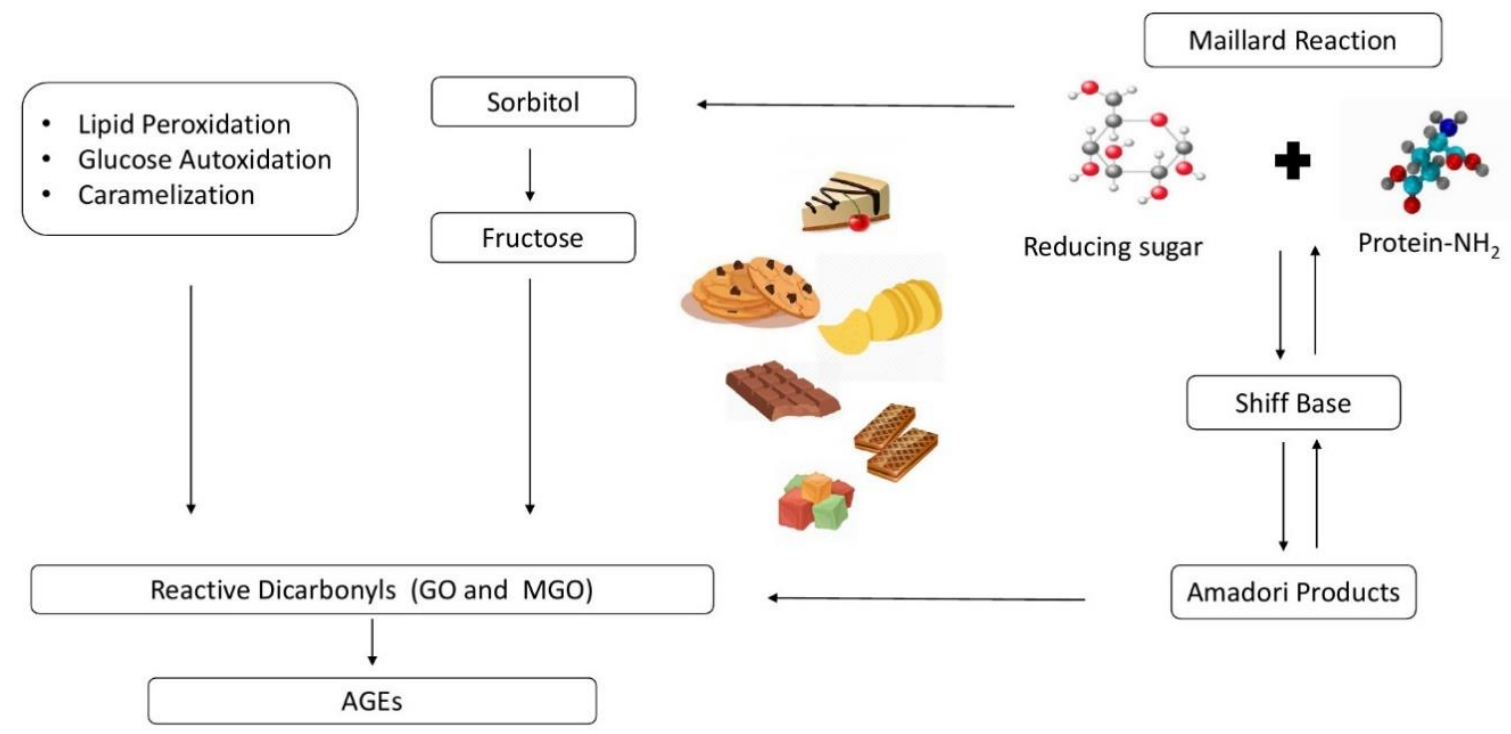

Figure 1. AGEs formation schema in snacks.

AGEs can also occur endogenously in the body as a part of normal metabolism [11]. Endogenous AGEs are formed during physiological glycation processes in organs, tissues and body fluids [12]. An excessive amount of AGEs in circulation is harmful to human health [13]. AGEs bind to cell surface receptors or body proteins and disrupt their structures and functions, causing oxidative stress and inflammation [14]. Damage due to excessive amount of AGE in tissues is directly related to the pathophysiology of metabolic diseases such as Type 2 Diabetes Mellitus, acute renal failure, Alzheimer's disease, dental health, allergies and polycystic ovary syndrome [12]. Considering all these health problems, it is of great importance to reduce the amount of dietary AGEs (dAGEs). In this context, it is important to know the AGEs content of the foods consumed.

AGEs contents vary according to nutrient composition, heat treatment, reactant concentration, water amount, and $\mathrm{pH}$. High fat and protein content, high-temperature heat treatment, low humidity and alkaline $\mathrm{pH}$ increase the formation of AGEs in foods [15]. Snack products are prone to AGE formation due to their high-temperature processing, high fat and low moisture content. [11].

A significant increase in consumption of snack foods due to bad eating habits may also be risky in terms of AGEs exposure.[15]. This study aims to determine the precursors of advanced glycation end products in snack foods. For this purpose, the amounts of GO and MGO, which are the AGEs precursors, were investigated in some snack foods.

\section{Materials and Methods}

\subsection{Material.}

Glyoxal, methylglyoxal, methanol, sodium acetate, 4-nitro-1,2-phenylenediamine, acetonitrile were obtained from Sigma-Aldrich (St. Louis, MO, USA). 


\subsection{Sampling.}

In this study, samples of biscuit (5), chocolate (5), wafer (4), cake (3), chips (3), cracker (2) and Turkish delight (1) were purchased from markets in Istanbul, Turkey. The content of the samples is given in Table II.

\subsection{Extraction and Derivatization of $G O$ and $M G O$.}

The extraction method used for GO and MGO in food samples was described by Mahar et al. (2010) with some modifications [16]. Firstly, each ground sample was weighed in a 50 $\mathrm{mL}$ falcon tube to be $2 \mathrm{~g}$, and $25 \mathrm{~mL}$ of methanol was added to it. Samples were extracted with an ultra-thorax homogenizer and centrifuged at $8000 \mathrm{rpm}$ for 5 minutes. In a $10 \mathrm{~mL}$ glass tube, $1 \mathrm{~mL}$ of $\mathrm{CH} 3 \mathrm{COONa}$ buffer $(0.1 \mathrm{M}, \mathrm{pH}: 3), 1 \mathrm{~mL}$ of liquid sample and $0.5 \mathrm{~mL}$ of derivatization solution (1\%4-nitro-1,2-phenylenediamine in methanol) were added. The mixture was incubated at $70{ }^{\circ} \mathrm{C}$ for 20 minutes. The samples were then filtered using a $0.45 \mu \mathrm{m}$ cellulose acetate filter and injected into HPLC.

\subsection{HPLC Determination of $G O$ and $M G O$.}

The HPLC conditions described by Mahar et al. (2010) were used after necessary modifications [16]. The HPLC system consisted of a Shimadzu LC 20AT pump with a Shimadzu SPD-20A UV / VIS detector. (Shimadzu Corporation, Kyoto, Japan). The mobile phase consisted of methanol: water: acetonitrile (42: 56: 2, v / v / v). The wavelength was 254 $\mathrm{nm}$. GO and MGO were separated with an Inertsil ODS-3, $250 \times 4.6 \mathrm{~mm}, 5 \mu \mathrm{m}$ column with a $1 \mathrm{~mL} / \mathrm{min}$ flow rate. The column oven temperature was $30^{\circ} \mathrm{C}$.

\section{Results and Discussion}

The HPLC chromatograms of GO and MGO standards and chocolate caramel are shown in Figure II and Figure III, respectively. The measured amount of GO and MGO in snack foods are presented in Table I. Additionally, the declared amount of macronutrients (carbohydrate, lipid and protein) and sugar on the label are shown in Table II.

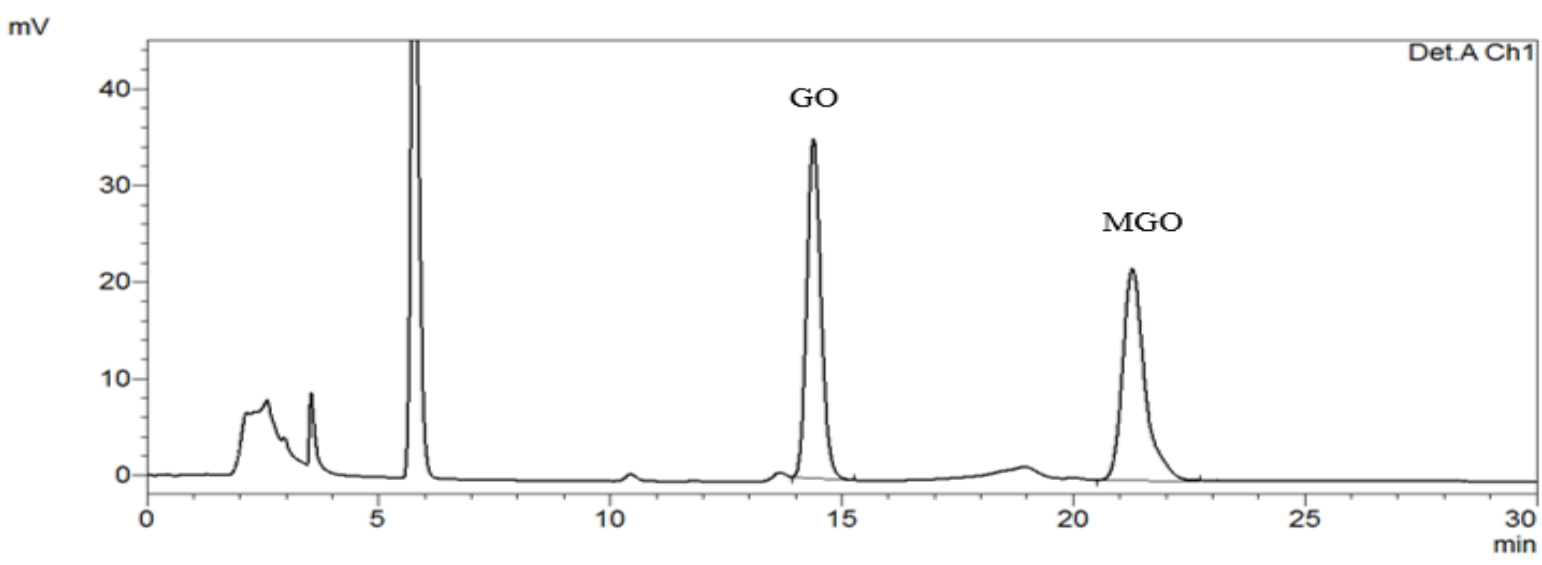

Figure 2. HPLC chromatogram of GO and MGO standards. 


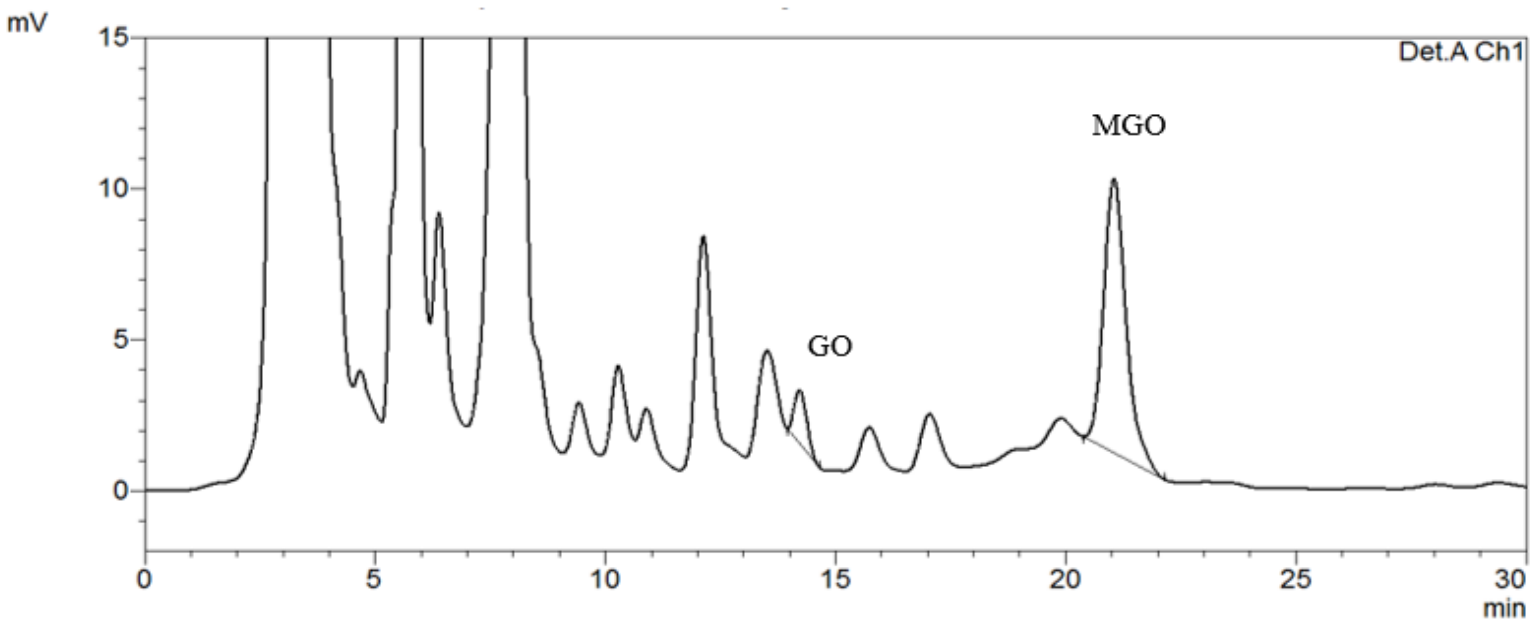

Figure 3. HPLC chromatogram of glyoxal and methylglyoxal in chocolate, mik, caramel.

Table 1. Content of GO and MGO in samples.

\begin{tabular}{l|l|l|l} 
Sample no & Sample type and main contents & $\mathbf{G O}(\boldsymbol{\mu g} / \mathbf{1 0 0} \mathbf{g})$ & $\mathbf{M G O}(\boldsymbol{\mu g} / \mathbf{1 0 0} \mathbf{g})$ \\
\hline 1 & Chocolate, coconut, caramel & 156 & 151 \\
\hline 2 & Chocolate, mik, caramel & 258 & 55 \\
\hline 3 & Chocolate, mik, caramel & 20 & 274 \\
\hline 5 & Chocolate, milk & 212 & 146 \\
\hline 6 & Chocolate, mik, caramel & 62 & 50 \\
\hline 7 & Biscuits, cocoa & 72 & 415 \\
\hline 9 & Biscuits,chocolate & 224 & 1573 \\
\hline 10 & Biscuits, cocoa & 65 & 216 \\
\hline 11 & Biscuits,chocolate & 35 & 32 \\
\hline 13 & Biscuits, cocoa & 45 & 40 \\
\hline 14 & Wafer, hazelnut, chocolate & 159 & 29 \\
\hline 15 & Wafer, chocolate & 112 & 67 \\
\hline 16 & Wafer, coconut & 45 & 75 \\
\hline 18 & Wafer, hazelnut & 380 & 1021 \\
\hline 19 & Cake, cacao & 157 & 772 \\
\hline 20 & Cake, fruit & 292 & 1213 \\
\hline 21 & Cake, cacao, hazelnut & 91 & 422 \\
\hline 22 & Chips, corn, peanut & 34 & 1045 \\
\hline 23 & Chips, corn, cheese & 28 & 1099 \\
\hline & Chips, corn, onion & 4 & 28 \\
\hline 17 & Cracker onion & 51 & 240 \\
\hline & Cracker, cheese & 7 & 226 \\
\hline & Turkish delight, pistachio & 684 & 603 \\
\hline
\end{tabular}

Table 2. Sample types with macronutrient contents, declared amount of carbohydrate, sugar, protein and fat.

\begin{tabular}{l|l|l|l|l|l} 
Sample no & Sample type and main contents & Carb $(\mathbf{g} / \mathbf{1 0 0 g})$ & Sugar $(\mathbf{g} / \mathbf{1 0 0 g})$ & $\mathbf{P r o t e i n}(\mathbf{g} / \mathbf{1 0 0 g})$ & $\mathbf{F a t}(\mathbf{g} / \mathbf{1 0 0 g})$ \\
\hline 1 & Chocolate, coconut, caramel & 59.7 & 42,6 & 7,2 & 29,1 \\
\hline 2 & Chocolate, mik, caramel & 75.2 & 37,7 & 5,8 & 17,4 \\
\hline 3 & Chocolate, mik, caramel & 54.7 & 28,8 & 2,8 & 12,84 \\
\hline 4 & Chocolate, milk & 66.6 & 66,6 & 4,1 & 17,9 \\
\hline 5 & Chocolate, mik, caramel & 60 & 58 & 6,2 & 25 \\
\hline 6 & Biscuits, cocoa & 70.6 & 35,8 & 5,3 & 22 \\
\hline 7 & Biscuits,chocolate & 71.4 & 0 & 6 & 20,6 \\
\hline 8 & Biscuits, cocoa & 71.9 & 19,7 & 4 & 19,7 \\
\hline 10 & Biscuits,chocolate & 67.5 & 21,7 & 4,3 & 16,1 \\
\hline 11 & Biscuits, cocoa & 66.1 & 22,6 & 3,6 & 16,9 \\
\hline 12 & Wafer, hazelnut, chocolate & 49.2 & 34,6 & 7,2 & 37,6 \\
\hline 13 & Wafer, chocolate & 60.2 & 45,1 & 5,4 & 24 \\
\hline 14 & Wafer, coconut & 59.2 & 40,1 & 5 & 30,8 \\
\hline 16 & Wafer, hazelnut & 70.92 & 39,17 & 4,58 & 21,2 \\
\hline 17 & Cake, cacao & 60.72 & 36,6 & 5,91 & 19,2 \\
\hline 18 & Cake, fruit & 60.57 & 2 & 4,37 & 17,4 \\
\hline 19 & Cake, cacao, hazelnut & 58.6 & 34,4 & 6,8 & 25,1 \\
\hline 20 & Chips, corn, peanut & 49.68 & 1 & 11,79 & 31,71 \\
\hline https://biointerfaceresearch.com/ & 60.4 & 3,1 & 4,6 & 26,5 \\
\cline { 2 - 5 } & Chips, corn, cheese & 62.6 & 2,5 & 5,6 & 21,7 \\
\hline
\end{tabular}




\begin{tabular}{l|l|l|l|l|l} 
Sample no & Sample type and main contents & Carb $(\mathbf{g} / \mathbf{1 0 0 g})$ & Sugar $(\mathbf{g} / \mathbf{1 0 0 g})$ & Protein $(\mathbf{g} / \mathbf{1 0 0 g})$ & Fat $(\mathbf{g} / \mathbf{1 0 0 g})$ \\
\hline 21 & Cracker onion & 67.5 & 0 & 7,5 & 15,3 \\
\hline 22 & Cracker, cheese & 75.4 & 0 & 8,6 & 11,5 \\
\hline 23 & Turkish delight, pistachio & 90 & 75 & 4 & 4
\end{tabular}

The measured amount of GO and MGO ranged between 20-258 $\mu \mathrm{g} / 100 \mathrm{~g}$ and 50-274 $\mu \mathrm{g} / 100 \mathrm{~g}$ in chocolates, respectively. Chocolate is a food usually consumed for pleasure due to its unique structure and flavor. For the production of chocolate, the basic ingredients are cocoa, sugar, butter, and milk. Chocolate-making consists of a multistep process including fermentation, drying, roasting and conching [17]. Roasting temperatures range from 120-150 ${ }^{\circ} \mathrm{C}$, with the roasting process lasting between 5-120 minutes[18]. Roasting time increases the formation of MR products, as well as AGEs [19]. Besides MR, sugar autoxidation and caramelization can contribute the formation of $\alpha$-DCs in chocolates. As seen in Table I, the amount of $\alpha$-DCs, GO and MGO, in snack products is high. Differences in the amount of GO and MGO between chocolate samples may be attributed to shelf life and storage conditions. Also, shelf life and storage conditions can increase lipid peroxidation, which accelerates AGEs formation [20]. Maasen et al. [21] indicated that chocolate contained considerable amounts of total dicarbonyls (26-555 mg/kg). They also found high concentrations of GO, possibly due to the fermentation step in chocolate processing. Similarly, most of our chocolate samples were relatively higher in GO.

The measured amount of GO and MGO ranged between 35-224 $\mu \mathrm{g} / 100 \mathrm{~g}$ and 32-1573 $\mu \mathrm{g} / 100 \mathrm{~g}$ in biscuits, respectively. Biscuit is a versatile snack in the food industry due to its attractive features such as longer shelf life, varied taste, and texture, including wider consumption [22]. Biscuit recipe consists of major ingredients, including flour, fat or oil, sugar, water and chemical leavening agents [23]. During biscuit baking, browning, caramelization and MR take place [24]. MR occurs when temperatures are above $50{ }^{\circ} \mathrm{C}$ or a $\mathrm{pH}$ between $4-$ 7. Besides, caramelization requires higher heat conditions (above $120^{\circ} \mathrm{C}$ ), $\mathrm{pH}<3$ or $\mathrm{pH}>9$, and low water activity [25]. High temperature, low water activity, baking time, humidity, $\mathrm{pH}$ and lipid peroxidation are the major influencing factors for AGEs formation in biscuits [25]. As seen in Table I, biscuit samples contain a high amount of GO and MGO. The factors mentioned above may be the reasons for high GO and MGO levels.

The measured amount of GO and MGO ranged between 45-380 $\mu \mathrm{g} / 100 \mathrm{~g}$ and 29-1021 $\mu \mathrm{g} / 100 \mathrm{~g}$ in wafers, respectively. Wafers are a crisp type of biscuits. Unlike biscuits, wafers are produced from a very fluid batter which is baked between heavy hot plates to produce thin sheets. The wafer recipe contains flour, sugar, oil or fat, milk powder and egg powder as major ingredients [26]. Wafers share similar risks with biscuits in terms of AGEs formation [22]. As it is seen in Table I, wafer samples in our study consist of high levels of GO and MGO, especially samples with hazelnuts. Due to their fat content in nuts, the formation of AGEs may occur through lipid peroxidation. In particular, being a fragmented state of hazelnuts in the wafer may increase lipid peroxidation. Lipid peroxidation has been studied as a degradation process of fats, especially as a factor in the deterioration of food quality. Malondialdehyde (MDA), a product of lipid peroxidation, is a highly reactive dialdehyde produced by the peroxidation of unsaturated fatty acids [27]. MDA is used as an indicator in the determination of lipid peroxidation as it can be easily analyzed by spectrophotometry [28]. As is seen in our results, high GO and MGO levels were observed in samples with high-fat content. Although MDA is a reliable indicator of lipid peroxidation, GO and MGO should not be neglected for lipid peroxidation, especially in processed snack foods. 
The measured amount of GO and MGO ranged between 91-292 $\mu \mathrm{g} / 100 \mathrm{~g}$ and 4221213 in cakes, respectively. Cakes are widely consumed snacks, attracted by their sweet taste and soft texture [29]. Wheat flour, sugar, egg and fat or oil are the main ingredients of cake [30]. Cakes are heat-treated at about $180-200{ }^{\circ} \mathrm{C}$ during the baking process. As seen in Table 1 cake samples have high levels of GO and MGO. The baking process can contribute to the $\alpha-$ DCs formation in cakes. Also, our results showed that fruit cake has the highest level of GO and MGO among cake samples. Yusufoğlu et al. [31] indicated that fruit-based heat-treated foods contain high levels of AGEs precursors due to caramelization and sugar autoxidation. Our results support the same findings with Yusufoğlu et al.

The measured amount of GO and MGO ranged between 4-34 $\mu \mathrm{g} / 100 \mathrm{~g}$ and 28-1099 $\mu \mathrm{g} / 100 \mathrm{~g}$ in chips, respectively. Chips are obtained by a frying process, which involves total cooking of the food in oil at a temperature oscillating between 160 and $200{ }^{\circ} \mathrm{C}$ [32]. As seen in Table II, chips have high-fat content. Due to high-fat content and heat temperature AGEs formation can occur in chips by lipid peroxidation. As seen in Table 1, chip samples have high $\alpha$-DCs, especially in MGO. Comparably, Uribari et al. . [11] indicated MGO content was significantly higher in french fries. Which may be related to fat content and dry heat processing. Chips with peanuts (sample 18) and chips with cheese (sample 19) have higher GO and MGO levels than chips with onion (sample 20). Both cheese and peanut increased the fat content of chips, this might increase the lipid peroxidation and result in high GO and MGO levels. Also, the fragmented structure of peanuts may accelerate the $\alpha$-DCs formation. Similar to our results, Uribarri et al. [11] found the highest dAGEs level per gram in dry-heat processed snack foods such as crackers, chips and cookies. This may be related to ingredients added to products such as butter, oil, cheese, eggs and nuts.

The measured amount of GO and MGO 7-51 $\mu \mathrm{g} / 100 \mathrm{~g}$ and 226-240 $\mu \mathrm{g} / 100 \mathrm{~g}$ in crackers, respectively. Crackers are one of the most consumed snacks with major ingredients such as flour, fat and salt. Crackers are one of the most consumed snacks which have major ingredients such as flour, fat and salt. Crackers are high-temperature heat-treated products with low moisture percentages [33]. Crackers present particularly high amounts of AGEs due to rich carbohydrate and fat content as well as cooking conditions [34]. Cengiz et al. [35] indicated in their study, salt content may contribute to the formation of GO and MGO in crackers during food processing. Cengiz et al. measured GO and MGO 94-1464 $\mu \mathrm{g} / 100 \mathrm{~g}$ and 123-661 $\mu \mathrm{g} /$ $100 \mathrm{~g}$ in crackers, respectively. The differences between studies may be attributed AGEs formation factors such as fat content, heat temperature and storage conditions.

The measured amount of GO and MGO ranged between and $684 \mu \mathrm{g} / 100 \mathrm{~g}$ and $603 \mu \mathrm{g}$ / 100 Turkish delight, respectively. Turkish delight is a traditional food prepared by mixing sugar, water, starch, citric acid, or tartaric acid in a wide container for $2-5 \mathrm{~h}$ at $125^{\circ} \mathrm{C}$ [36]. It is seen from the results that, Turkish delight sample had a high amount of both GO and MGO. According to the TURKOMP, the glucose, fructose, sucrose, and total sugar content are ranged between 19.20-20.93 g/100 g, 12.43-21.78 g/100 g, 20.41-24.95 g/100 g, and 58.31-66.3 $\mathrm{g} / 100 \mathrm{~g}$, respectively (TURKKOMP,2021). As seen in Table II, the high sugar content declared on the label might contribute to the $\alpha$-DCs formation by caramelization reaction due to high temperature.

Briefly, our results showed that AGE precursor $\alpha$-DCs are high in Turkish snack foods. Macronutrient composition and sugar content may affect the GO and MGO levels. Glucose autoxidation, caramelization, Maillard reaction and lipid peroxidation may contribute to the 
occurrence of $\alpha$-DCs. High heat treatment, food processing techniques such as baking, roasting, frying, shelf life and storage conditions may accelerate the formation of AGEs.

\section{Conclusions}

$\alpha$-DCs are highly reactive molecules and resulting in the formation of AGEs. GO and MGO are $\alpha$-DCs, which are major precursors of AGEs. Increased AGEs levels in the human body are related to metabolic diseases such as Type 2 Diabetes Mellitus, acute renal failure, Alzheimer's disease, dental health, allergies and polycystic ovary syndrome. It is important to reduce dAGEs exposure by eliminating high AGEs contain foods from the diet. In this context, it is important to determine the AGEs in foods. Snack foods are convention to AGEs formation due to fat and sugar content, high heat treatment process and long shelf life. We analyzed GO and MGO in snack foods in this study, including chocolates, biscuits, wafers, cakes, chips, crackers, and Turkish delight. We found that snack foods contain high levels of potential AGEs. We also observed that snacks with added cheese, peanut, hazelnut and fruit may increase the MGO levels. Snack foods are not favorable for healthy eating, besides they contain high levels of potential AGEs. It is necessary to limit snack food consumption to reduce dAGEs exposure and risk of AGEs related metabolic disease.

\section{Funding}

This research received no external funding.

\section{Acknowledgments}

We want to thank Istanbul Sabahattin Zaim University for their support.

\section{Conflicts of Interest}

The authors declare no conflict of interest.

\section{References}

1. Rauber, F.; Da Costa Louzada, M.L.; Steele, E.M.; Millett, C.; Monteiro, C.A.; Levy, R.B. Ultra-Processed Food Consumption and Chronic Non-Communicable Diseases-Related Dietary Nutrient Profile in the UK (2008-2014). Nutrients 2018, 10, https://doi.org/10.3390/nu10050587

2. Sharma, C.; Kaur, A.; Thind, S.S.; Singh, B.; Raina, S. Advanced glycation End-products (AGEs): an emerging concern for processed food industries. J. Food Sci. Technol. 2015, 52, 7561-7576, https://doi.org/10.1007/s13197-015-1851-y.

3. Kumar Pasupulati, A.; Chitra, P.S.; Reddy, G.B. Advanced glycation end products mediated cellular and molecular events in the pathology of diabetic nephropathy. Biomol. Concepts 2016, 7, 293-309, https://doi.org/10.1515/bmc-2016-0021.

4. Rabbani, N.; Thornalley, P.J. Advanced glycation end products in the pathogenesis of chronic kidney disease. Kidney Int. 2018, 93, 803-813, https://doi.org/10.1016/j.kint.2017.11.034.

5. Vistoli, G.; De Maddis, D.; Cipak, A.; Zarkovic, N.; Carini, M.; Aldini, G. Advanced glycoxidation and lipoxidation end products (AGEs and ALEs): an overview of their mechanisms of formation. Free Radical Res. 2013, 47, 3-27, https://doi.org/10.3109/10715762.2013.815348.

6. Luevano-Contreras, C.; Chapman-Novakofski, K. Dietary Advanced Glycation End Products and Aging. Nutrients 2010, 2, https://doi.org/10.3390/nu2121247.

7. Sergi, D.; Boulestin, H.; Campbell, F.M.; Williams, L.M. The Role of Dietary Advanced Glycation End Products in Metabolic Dysfunction. Mol. Nutr. Food Res. 2021, 65, 1900934, https://doi.org/10.1002/mnfr.201900934. 
8. Gupta, R.K.; Gupta, K.; Sharma, A.; Das, M.; Ansari, I.A.; Dwivedi, P.D. Maillard reaction in food allergy: Pros and cons. Crit. Rev. Food Sci. Nutr. 2018, 58, 208-226, https://doi.org/10.1080/10408398.2016.1152949.

9. Zhou, Q.; Cheng, K.-W.; Xiao, J.; Wang, M. The multifunctional roles of flavonoids against the formation of advanced glycation end products (AGEs) and AGEs-induced harmful effects. Trends Food Sci. Technol. 2020, 103, 333-347, https://doi.org/10.1016/j.tifs.2020.06.002.

10. Nie, C.; Li, Y.; Qian, H.; Ying, H.; Wang, L. Advanced glycation end products in food and their effects on intestinal tract. Crit. Rev. Food Sci. Nutr. 2020, 1-13, https://doi.org/10.1080/10408398.2020.1863904.

11. Uribarri, J.; Woodruff, S.; Goodman, S.; Cai, W.; Chen, X.; Pyzik, R.; Yong, A.; Striker, G.E.; Vlassara, H. Advanced glycation end products in foods and a practical guide to their reduction in the diet. J. Am. Diet. Assoc. 2010, 110, 911-916, https://doi.org/10.1016/j.jada.2010.03.018.

12. Zhang, Q.; Wang, Y.; Fu, L. Dietary advanced glycation end-products: Perspectives linking food processing with health implications. Comprehensive Reviews in Food Science and Food Safety 2020, 19, 2559-2587, https://doi.org/10.1111/1541-4337.12593\%20.

13. Uribarri, J.; del Castillo, M.D.; de la Maza, M.P.; Filip, R.; Gugliucci, A.; Luevano-Contreras, C.; MacíasCervantes, M.H.; Markowicz Bastos, D.H.; Medrano, A.; Menini, T.; Portero-Otin, M.; Rojas, A.; Sampaio, G.R.; Wrobel, K.; Wrobel, K.; Garay-Sevilla, M.E. Dietary Advanced Glycation End Products and Their Role in Health and Disease. Adv. Nutr. 2015, 6, 461-473, https://doi.org/10.3945/an.115.008433.

14. Perrone, A.; Giovino, A.; Benny, J.; Martinelli, F. Advanced Glycation End Products (AGEs): Biochemistry, Signaling, Analytical Methods, and Epigenetic Effects. Oxid. Med. Cell. Longev. 2020, 2020, 3818196, https://doi.org/10.1155/2020/3818196.

15. Zahedi, H.; Kelishadi, R.; Heshmat, R.; Motlagh, M.E.; Ranjbar, S.H.; Ardalan, G.; Payab, M.; Chinian, M.; Asayesh, H.; Larijani, B.; Qorbani, M. Association between junk food consumption and mental health in a national sample of Iranian children and adolescents: The CASPIAN-IV study. Nutrition 2014, 30, 1391-1397, https://doi.org/10.1016/j.nut.2014.04.014.

16. Mahar, K.P.; Khuhawar, M.Y.; Kazi, T.G.; Abbasi, K.; Channer, A.H. Quantitative analysis of glyoxal, methyl glyoxal and dimethyl glyoxal from foods, beverages and wines using HPLC and 4-nitro-1, 2phenylenediamine as derivatizing reagent. Asian J. Chem. 2010, 22, 6983-6990, http://www.asianjournalofchemistry.co.in/User/ViewFreeArticle.aspx?ArticleID=22_9_48.

17. Di Mattia, C.D.; Sacchetti, G.; Mastrocola, D.; Serafini, M. From Cocoa to Chocolate: The Impact of Processing on In Vitro Antioxidant Activity and the Effects of Chocolate on Antioxidant Markers In Vivo. Front. Immunol. 2017, 8, 1207, https://dx.doi.org/10.3389\%2Ffimmu.2017.01207.

18. Rojas S, M.; Chejne, F.; Ciro, H.; Montoya, J. Roasting impact on the chemical and physical structure of Criollo cocoa variety (Theobroma cacao L). J. Food Process Eng. 2020, 43, e13400, https://doi.org/10.1111/jfpe.13400.

19. Barišić, V.; Kopjar, M.; Jozinović, A.; Flanjak, I.; Ačkar, Đ.; Miličević, B.; Šubarić, D.; Jokić, S.; Babić, J. The Chemistry behind Chocolate Production. 2019, 24, 3163, https://doi.org/10.3390/molecules24173163.

20. Ravichandran, G.; Lakshmanan, D.K.; Raju, K.; Elangovan, A.; Nambirajan, G.; Devanesan, A.A.; Thilagar, S. Food advanced glycation end products as potential endocrine disruptors: An emerging threat to contemporary and future generation. Environ. Int. 2019, 123, 486-500, https://doi.org/10.1016/j.envint.2018.12.032.

21. Maasen, K.; L.J.M. Scheijen, J.; Opperhuizen, A.; Stehouwer, C.D.A.; Van Greevenbroek, M.M.; Schalkwijk, C.G. Corrigendum to "Quantification of dicarbonyl compounds in commonly consumed foods and drinks; presentation of a food composition database for dicarbonyls" [Food Chemistry, 339 (2020) 128063]. Food Chem. 2021, 344, 128578, https://doi.org/10.1016/j.foodchem.2020.128578.

22. Arepally, D.; Reddy, R.S.; Goswami, T.K.; Datta, A.K. Biscuit baking: A review. LWT 2020, 131, 109726, https://doi.org/10.1016/j.lwt.2020.109726.

23. Mancebo, C.M.; Picón, J.; Gómez, M., Effect of flour properties on the quality characteristics of gluten free sugar-snap cookies. LWT-Food Sci. Technol. 2015, 64, 264-269, https://doi.org/10.1016/j.lwt.2015.05.057.

24. Chevallier, S.; Colonna, P.; Della Valle, G.; Lourdin, D. Contribution of Major Ingredients during Baking of Biscuit Dough Systems. Journal of Cereal Science 2000, 31, 241-252, https://doi.org/10.1006/jcrs.2000.0308

25. Kroh, L.W. Caramelisation in food and beverages. Food Chem. 1994, 51, 373-379, https://doi.org/10.1016/0308-8146(94)90188-0.

26. Manley, D. 30 - Wafer biscuits. In Manley's Technology of Biscuits, Crackers and Cookies (Fourth Edition), Manley, D., Ed. Woodhead Publishing: 2011; 353-371, https://doi.org/10.1533/9780857093646.3.353. 
27. Dei, R.; Takeda, A.; Niwa, H.; Li, M.; Nakagomi, Y.; Watanabe, M.; Inagaki, T.; Washimi, Y.; Yasuda, Y.; Horie, K.; Miyata, T.; Sobue, G. Lipid peroxidation and advanced glycation end products in the brain in normal aging and in Alzheimer's disease. Acta Neuropathol. 2002, 104, 113-122, https://doi.org/10.1007/s00401-002-0523-y.

28. Tsikas, D. Assessment of lipid peroxidation by measuring malondialdehyde (MDA) and relatives in biological samples: Analytical and biological challenges. Anal. Biochem. 2017, 524, 13-30, https://doi.org/10.1016/j.ab.2016.10.021.

29. Xu, J.; Zhang, Y.; Wang, W.; Li, Y. Advanced properties of gluten-free cookies, cakes, and crackers: A review. Trends Food Sci. Technol. 2020, 103, 200-213, https://doi.org/10.1016/j.tifs.2020.07.017.

30. Wilderjans, E.; Luyts, A.; Brijs, K.; Delcour, J.A. Ingredient functionality in batter type cake making. Trends Food Sci. Technol. 2013, 30, 6-15, https://doi.org/10.1016/j.tifs.2013.01.001.

31. Yusufoğlu, B.; Yaman, M.; Karakuş, E. Determination of the most potent precursors of advanced glycation end products in some high-sugar containing traditional foods using high-performance liquid chromatography. J. Food Process. Preserv. 2020, 44, e14708, https://doi.org/10.1111/jfpp.14708.

32. Trujillo-Agudelo, S.; Osorio, A.; Gómez, F.; Contreras-Calderón, J.; Mesías-Garcia, M.; Delgado-Andrade, C.; Morales, F.; Vega-Castro, O. Evaluation of the application of an edible coating and different frying temperatures on acrylamide and fat content in potato chips. J. Food Process Eng. 2020, 43, e13198, https://doi.org/10.1111/jfpe.13198.

33. Sykes, G.;Davidson, I., Biscuit, cookie and cracker process and recipes, 1st ed.: Elsevier, Acedemic Press: Unated States, 2020. 145-164. ISBN: 9780128206133

34. Bettiga, A.; Fiorio, F.; Di Marco, F.; Trevisani, F.; Romani, A.; Porrini, E.; Salonia, A.; Montorsi, F.; Vago, R. The Modern Western Diet Rich in Advanced Glycation End-Products (AGEs): An Overview of Its Impact on Obesity and Early Progression of Renal Pathology. Nutrients 2019, 11, https://doi.org/10.3390/nu11081748.

35. Cengiz, S.; Kişmiroğlu, C.; Çebi, N.; Çatak, J.; Yaman, M. Determination of the most potent precursors of advanced glycation end products (AGEs) in chips, crackers, and breakfast cereals by high performance liquid chromatography (HPLC) using precolumn derivatization with 4-nitro-1,2-phenlenediamine. Microchem. J. 2020, 158, 105170, https://doi.org/10.1016/j.microc.2020.105170.

36. Batu, A.; Kirmaci, B. Production of Turkish delight (lokum). Food Res. Int. 2009, 42, 1-7, https://doi.org/10.1016/j.foodres.2008.08.007.

37. TURKKOMP, Turkish food composition database. Available online: http://www.turkomp.gov.tr/main (accessed on 16 January 2021). 